\title{
Olanzapine-induced methylation alters cadherin gene families and associated pathways implicated in psychosis
}

Melkaye G Melka ${ }^{1}$, Christina A Castellani ${ }^{1}$, Nagalingam Rajakumar ${ }^{2}$, Richard O'Reilly ${ }^{2}$ and Shiva M Singh ${ }^{1 *}$

\begin{abstract}
Background: The complex aetiology of most mental disorders involves gene-environment interactions that may operate using epigenetic mechanisms particularly DNA methylation. It may explain many of the features seen in mental disorders including transmission, expression and antipsychotic treatment responses. This report deals with the assessment of DNA methylation in response to an antipsychotic drug (olanzapine) on brain (cerebellum and hippocampus), and liver as a non-neural reference in a rat model. The study focuses on the Cadherin/protocadherins encoded by a multi-gene family that serve as adhesion molecules and are involved in cell-cell communication in the mammalian brain. A number of these molecules have been implicated in the causation of schizophrenia and related disorders.
\end{abstract}

Results: The results show that olanzapine causes changes in DNA methylation, most specific to the promoter region of specific genes. This response is tissue specific and involves a number of cadherin genes, particularly in cerebellum. Also, the genes identified have led to the identification of several pathways significantly affected by DNA methylation in cerebellum, hippocampus and liver. These included the Ga12/13 Signalling ( $p=9.2 \mathrm{E}-08)$ and Wnt signalling $(p=0.01)$ pathways as contributors to psychosis that is based on its responsiveness to antipsychotics used in its treatment.

Conclusion: The results suggest that DNA methylation changes on the promoter regions of the Cadherin/ protocadherin genes impact the response of olanzapine treatment. These impacts have been revealed through the identified pathways and particularly in the identification of pathways that have been previously implicated in psychosis.

\section{Background}

Cadherins are involved in neurodevelopment, nerve cell migration and cell-to-cell interaction and therefore it follows that they may regulate the pathogenesis of psychosis [1]. For example, previous studies suggested the importance of investigating epigenetic control of PcdhXY with respect to psychiatric disorders [2]. Interestingly, previous studies have suggested that epigenetic modifications regulate the expression of clustered protocadherin genes (Pcdhs) [3]. In mammals, more than 50 Pcdh genes are categorized into three clusters $P c d h-\alpha, P c d h-\beta$ and Pcdh- $\gamma$ encoding diversified proteins mainly expressed in the nervous system [3-5]. Some protocadherins (Pcdh1

\footnotetext{
* Correspondence: ssingh@uwo.ca

${ }^{1}$ Molecular Genetics Unit, Department of Biology, The University of Western Ontario, London, ON N6A 5B7, Canada

Full list of author information is available at the end of the article
}

and $P c d h 7)$ are regulated by Methyl-CpG-binding protein, $M e C P 2$, which is a protein that is strongly associated with epigenetic regulation [6].

Aberrant promoter methylation of cadherin family genes has been implicated in complex human disorders [7]. For example, Pcdh10, a novel tumor suppresser gene is found to be downregulated by hypermethylation in various cancer cases [8-10] corroborating the evidence that epigenetics plays a role in complex disorders. Further, the high expression of Pcdh $\alpha v 8$ in mouse neuroblastoma cell lines was found to be associated with demethylation of the 5' regulatory region of the gene [11]. In the same study, a dynamic change in methylation of Pcdh genes was observed. The 5' region of the Pcdhov4 gene was 99\% methylated in neuroblastoma cells and $\sim 35 \%$ methylated in the cortex of mice. On the contrary, the 5 ' region of the Pcdh $\alpha v 8$ was reported to be $99.1-100 \%$ methylated in neuroblastoma cell lines 
and $5 \%$ methylated in the cortex of the mouse strain C57BL/6 [11].

Although it is possible that aberrant metabolomics may be due to mutation in a single gene or be the effect of a single environment, emerging literature argues that most often the development of complex diseases and disorders represents a complex interaction of multiple genes and multiple environments [12]. This is true in most behavioral disorders that have complex aetiology involving several genes and environment [13]. Ultimately, the two contributors enact their effect by altering cellular metabolomics through changes in gene expression via epigenetic modifications such as DNA methylation [14]. However, an assessment of the mechanistic basis of the effect of environment has been arduous as an environment may cause aberration via its effect on the gene(s). This offers renewed hope for the treatment of complex disorders, as it may be possible to manipulate DNA methylation, and subsequently alter gene expression to affect metabolomic aberrations and facilitate a cure or decreased severity of symptoms. Also, this paradigm of disease causation is expected to be instrumental in identifying mechanisms of actions of antipsychotics, such as olanzapine.

Mental disorders including psychosis are difficult to treat. Antipsychotics have variable responses and their mechanism of action is imprecise. We have assessed the mechanisms of action of olanzapine, a commonly used antipsychotic medication. The results argue that olanzapine may improve the mental outcome of patients by altering the methylation profile of genes implicated in disease-specific pathways. Specifically, our studies reported changes in the methylation of genes implicated in the dopamine pathways in the hippocampus and cerebellum in a rat model [15]. Interestingly, in a genome-wide assessment, our studies showed methylation changes in the genes of a number of pathways that may alter metabolomics leading to the efficacy as well as side effects of olanzapine [15]. These results offer a novel paradigm to reveal critical genes and pathways by identifying changes in methylation in response to drugs that offer relief or cure for the disease symptoms. Here we will present data on genes of the cadherin and protocadherin $(P c d h)$ family that are preferentially affected by olanzapine. The clustered protocadherin $(P c d h)$ genes [16] encode a group of diverse cadherin-related transmembrane proteins, and are expressed in the brain [17]. They generate vast single-cell diversity in the brain [18]. They represent $\mathrm{Ca}_{2}^{+}$-dependent cell adhesion molecules that are critical in vertebrate nervous development [19] and maintenance of neural circuitry [20]. The expression of this cluster of genes is regulated by a complex mechanism at the level of transcription [21] that may include gene specific DNA methylation [22]. Given the critical role of cadherins in brain development and function it is not surprising that genome-wide analysis for a number of mental disorders have implicated defects in cadherin genes. These include complex disorders, such as intellectual disability [23] autism [24] schizophrenia [25,26] and bipolar disorders [27]. This report adds to this complex literature suggesting that a commonly used antipsychotic drug, olanzapine, affects methylation of the promoter regions of cadherin family genes in the rat brain. The effect of olanzapine is tissue specific, particularly affecting several gene promoters in cerebellum and may have implications in the therapeutic response.

\section{Methods \\ Rats}

Adult male Sprague-Dawley rats of 12 weeks of age (250 300 g) were purchased from Charles River, PQ, Canada. Upon arrival, rats were placed (2 per cage) in standard acrylic cages and subjected to the treatment protocol. They housed in controlled humidity and temperature on a 12-hour light/dark cycle (lights on at 7:00 a.m.). They were fed standard rat chow (LabDiet) and tap water ad libitum.

\section{Ethical approval}

The Institutional Animal Care Committee of the University of Western Ontario had approved all animal-related procedures used in this study following the Canadian and National Institute of Health Guides on animal experimentation. Also, the manuscript reporting followed the ARRIVE (Animal Research: Reporting of In Vivo Experiments) guidelines.

\section{Olanzapine treatment}

Before the commencement of olanzapine treatment, animals were weighed and divided into two treatment groups with comparable means of weight. Their stressinduced locomotor activity (following a 5 min tail pinch) was recorded for $30 \mathrm{~min}$ using an automated open-field activity chamber (San Diego Instruments, San Diego, CA, USA). A computer that detects the disruption of photocell beams recorded the number of beam breaks per five minutes for half an hour as the animal moves. Rats then received injections of olanzapine (Zyprexa, Lilly, IN, USA; $2.5 \mathrm{mg} / \mathrm{kg}$, i.m.; $\mathrm{n}=8$ ) or vehicle (phosphate buffered saline (PBS); $\mathrm{n}=8$ ) between $1: 30 \mathrm{pm}$ and 3:00 pm daily for 19 days. On day 20, eighteen hours after the last olanzapine/vehicle injection, rats were subjected to stress-induced locomotor activity to assess the therapeutic efficacy of chronic olanzapine. Significantly reduced locomotor activity of olanzapine treated rats indicated the therapeutic efficacy of the drug administered, which was comparable to the dosing paradigm employed in previous studies [28]. 


\section{Genomic DNA extraction}

Rats were decapitated without anaesthesia, brain tissues were micro-dissected promptly in ice-cold PBS; and three random biopsy punches through cerebellum, hippocampus, and liver were obtained. Individual samples (three random biopsy punches of each tissue composed one sample) from each rat were kept separately and flash frozen in liquid nitrogen. The genomic DNA was isolated from olanzapine-treated $(n=2)$ and saline control $(n=2)$ samples of cerebellum, hippocampus and liver. Genomic DNA was isolated from the interphase layer of TRIzol using sodium citrate, followed by ethanol precipitation and purification using the QIAamp ${ }^{\circ}$ DNA Micro Kit (QIAGEN, Valencia, CA). DNA was then quantified using a NanoDrop ND-1000 spectrophotometer (Thermo Fisher Scientific Inc., Wilmington, DE) and all samples had $\mathrm{OD}_{260} / \mathrm{OD}_{280} \mathrm{~nm}$ ratios of $1.8-2.0$ and $\mathrm{OD}_{260} / \mathrm{OD}_{230} \mathrm{~nm}$ ratios of $2.0-2.4$.

\section{Methylated DNA immunoprecipitation}

This study has used methylated DNA immunoprecipitation (MeDIP) to investigate genome-wide DNA methylation in a rat model [29] The MeDIP sample labeling, hybridization, and processing were performed at Arraystar Inc. (Rockville, Maryland, USA). The immunoprecipitated DNA was eluted and purified by phenol chloroform extraction and ethanol precipitation. The total input and immunoprecipitated DNA were labeled with Cy3- and Cy5-labeled random 9-mers, respectively, and hybridized to NimbleGen RN34 Meth $3 \times 720 \mathrm{~K}$ CpG plus Promoter array, which is a single array design containing all known CpG Islands annotated by UCSC and all well-characterized RefSeq promoter regions (from about $-3.88 \mathrm{~kb}$ to $+0.97 \mathrm{~kb}$ of the transcription start sites [TSSs]) covered by $\sim 720,000$ probes. Scanning was performed with the Axon GenePix 4000B microarray scanner. Therefore, the array design would capture the global changes in methylation.

Data analysis involved the comparison of differentially enriched regions between drug exposed (E) and control (C) rats, the $\log _{2}$-ratio values were averaged and then used to calculate the $\mathrm{M}^{\prime}$ value $\left[\mathrm{M}^{\prime}=\right.$ Average $\left(\log _{2} \mathrm{MeDIPE} /\right.$ InputE) - Average ( $\log _{2} \mathrm{MeDIPC/InputC)}$ ] for each probe. A NimbleScan sliding-window peak-finding algorithm was run on this data to find the differential enrichment peaks (DEP). Using an R script program, a hierarchical clustering analysis was completed. The probe data matrix was obtained by using PeakScores from differentially methylated regions selected by DEP analysis. This analysis used a "PeakScore" $\geq 2$ to define the DEPs, which is equivalent to the average $p$-value $\leq 0.01$, for all probes within the peak. In this study, we have specifically analyzed 17 Cadherin family genes and their methylation status in cerebellum and hippocampus with liver as a non-neural cell types following olanzapine treatment of experimental rats (Table 1).

\section{Pathway analysis of array results}

The affected Cadherin family genes were then subjected to ingenuity pathway analysis (Ingenuity System Inc, CA, USA) [http://www.ingenuity.com/]. Transcription factor binding sites of $C d h 13$ that showed increased methylation in cerebellum were identified using CTCFBSDB 2.0 [30]. This analysis was done as a representative for all cadherin genes affected by olanzapine-induced DNA methylation.

\section{Results}

Recently, we reported that therapeutic olanzapine causes an increase in 1294 genes and a decrease in 565 genes in the cerebellum of treated rats [15]. This response is tissue specific and only $10 \%$ of the genes affected were shared between cerebellum and hippocampus. With respect to cadherin genes, we report that the promoter regions of 11 Cadherin family genes have olanzapineinduced DNA methylation changes in the cerebellum as compared to matched controls (Table 1). Of those genes, five showed significantly increased methylation, while six of them showed decreased methylation $(p<0.01)$. In comparison to the results on cerebellum, three cadherin genes (Cdh17, Cdh23, Pcdh7) had increased methylation and one gene (Pcdhga8) showed decreased methylation in hippocampus. Also, two cadherin genes (Cdh5 and Cdh11) had increased methylation and two genes (Pcdhga 8 and Pcdhgb7) showed decreased methylation in the liver. The cadherin genes in the rat genome that are affected by olanzapine-induced DNA methylation are dispersed over different chromosomes including chromosome 2, 3, 15, 18, 19, 20 and $\mathrm{X}$.

For the identification of each methylation difference, we compared the Manhattan plot of individual cadherin genes. It is shown in Figure 1 using $C d h 13$ as a model. In this figure, the peak of differential methylation (Figure 1A), the genomic region of $C d h 13$ on the rat genome (Figure 1B) and the sequence depicting the promoter region (Figure 1C) are shown. It has allowed us to identify regulatory features including a CTCF binding site. As shown in Figure $1 \mathrm{C}$, the methylation changes were observed in the surrounding Cs and CpGs suggesting the global effect of olanzapine. The sequence presented in the figure showed differential methylation, which included the identified CTCF binding site in the promoter region of the gene.

Next, we used pathway analysis to identify major pathways and systems (Table 2) that may be affected by the observed olanzapine-induced methylation changes in the cadherin family genes in hippocampus, cerebellum and liver listed in Table 1. Interestingly, pathway analysis involving these genes revealed the most significant pathways 
Table 1 List of the Cadherin genes with their promoter regions affected by olanzapine-induced methylation

\begin{tabular}{|c|c|c|c|c|c|c|c|c|}
\hline Gene name & $C$ & Olz & Chr & Strand & TSS & TTS & Peak to TSS & Accession \\
\hline \multicolumn{9}{|l|}{ Cerebellum } \\
\hline Pcdh7 & + & - & 14 & - & 57323892 & 56609035 & -3782 & NM_001004087 \\
\hline Pcdh8 & - & + & 15 & - & 61060741 & 61056993 & -252 & NM_022868 \\
\hline Pcdh9 & - & + & 15 & - & 76737306 & 75827179 & -2160 & NM_001191688 \\
\hline Pcdha11 & + & - & 18 & + & 29728602 & 29928030 & -1925 & NM_199486 \\
\hline Pcdhag & - & + & 18 & + & 29715234 & 29928031 & -3346 & NM_199508 \\
\hline Pcdhga5 & + & - & 18 & + & 30600857 & 30754205 & 914 & NM_001037137 \\
\hline Pcdh19 & - & + & $x$ & - & 121209099 & $1.21 E+08$ & -777 & NM_001169129 \\
\hline Cdh1 & + & - & 19 & + & 36442692 & 36512091 & -92 & NM_031334 \\
\hline Cdh13 & - & + & 19 & + & 48507172 & 49575122 & -501 & NM_138889 \\
\hline Pcdh18 & + & - & 2 & - & 138629181 & $1.39 E+08$ & -3583 & NM_001100524 \\
\hline Cdh22 & + & - & 3 & - & 156275540 & $1.56 \mathrm{E}+08$ & 94 & NM_019161 \\
\hline \multicolumn{9}{|c|}{ Hippocampus } \\
\hline Pcdhgas & + & - & 18 & + & 30635032 & 30754205 & -3889 & NM_001037156 \\
\hline Cdh17 & - & + & 5 & + & 26047221 & 26099173 & -1218 & NM_053977 \\
\hline Cdh23 & - & + & 20 & - & 28016145 & 27622048 & -214 & NM_053644 \\
\hline Pcdh7 & - & + & 14 & - & 57323892 & 56609035 & -1007 & NM_001004087 \\
\hline \multicolumn{9}{|l|}{ Liver } \\
\hline Pcdhgb7 & + & - & 18 & + & 30660279 & 30754207 & -1029 & NM_001012215 \\
\hline Cdh11 & - & + & 19 & + & 2225208 & 2382805 & 923 & NM_053392 \\
\hline Cdh5 & - & + & 19 & - & 816108 & 779349 & -46 & NM_001107407 \\
\hline Pcdhgas & + & - & 18 & + & 30635032 & 30754205 & -3889 & NM_001037156 \\
\hline
\end{tabular}

C: Control; Olz: olanzapine treated; Chr: chromosome; +: increase in DNA methylation; -: decrease in DNA methylation.

including the Go12/13 signalling ( $p=9.2 \mathrm{E}-08$ ) (Figure $2 \mathrm{~A}$ ), RhoGDI signalling $(\mathrm{p}=4.8 \mathrm{E}-07)$ (Figure $2 \mathrm{~B}$ ) and $\mathrm{Wnt} / \beta$ catenin signalling $(p=1.2 \mathrm{E}-02)$ pathways (Figure $2 \mathrm{C}$ ). They affect molecular and cellular functions associated with cell-to-cell signalling and interactions $(p=6.13 \mathrm{E}-04$ 3.01E-02) and may affect tissue, nervous system dynamics and behaviour. In doing so, differential methylation of genes involved in the pathway suggested that olanzapine affects the physiological cadherin system $(p=6.13 \mathrm{E}-04$ 9.76E-03) (Table 2).

\section{Discussion}

Cell-cell communication is an essential feature of multicellular organisms. It is particularly critical in the mammalian brain, where molecules involved in cell-cell interactions such as adhesion and exchange of information provide the foundation for neurodevelopment as well as proper functioning of the neural network. Not surprisingly, mammalian brain is rich in such molecules. Also, the exceptional richness and diversity of these molecules is often accounted for by their evolution, by multi-gene families and by diversity of regulatory mechanisms. For example, adhesion molecules such as cadherins that constitute a super-family of transmembrane receptors and mediate $\mathrm{Ca}^{2+}$-dependent cell to cell hemophilic interactions are encoded by $\sim 100$ genes in humans [31]. Also, the organization of these genes allows differential expression including gene specific DNA methylation and differential splicing to facilitate expression of specific cadherins in different cells and cell types [32]. As it stands, the molecular basis of the cadherins is still unclear. What is known is that cells expressing a given cadherin adhere preferentially to those expressing the same cadherin subtype [33]. Also, the combination of qualitative and quantitative differences likely confers cell type-specific adhesion affinities on individual cells [34]. They provide the foundation for target recognition, synapse formation and signalling, which are critical features of any neural network [35].

The results included in this study show that olanzapine affects the methylation status of the cadherin gene promoters. Given the involvement of cadherin genes in a number of mental disorders including psychosis, it is understandable that several cadherin genes are differentially methylated in response to olanzapine. Also, this difference is prominent in the cerebellum that is involved in cognitive processing and emotional control including attention, executive control, language, working memory, pain, emotion, and addiction in addition to its 


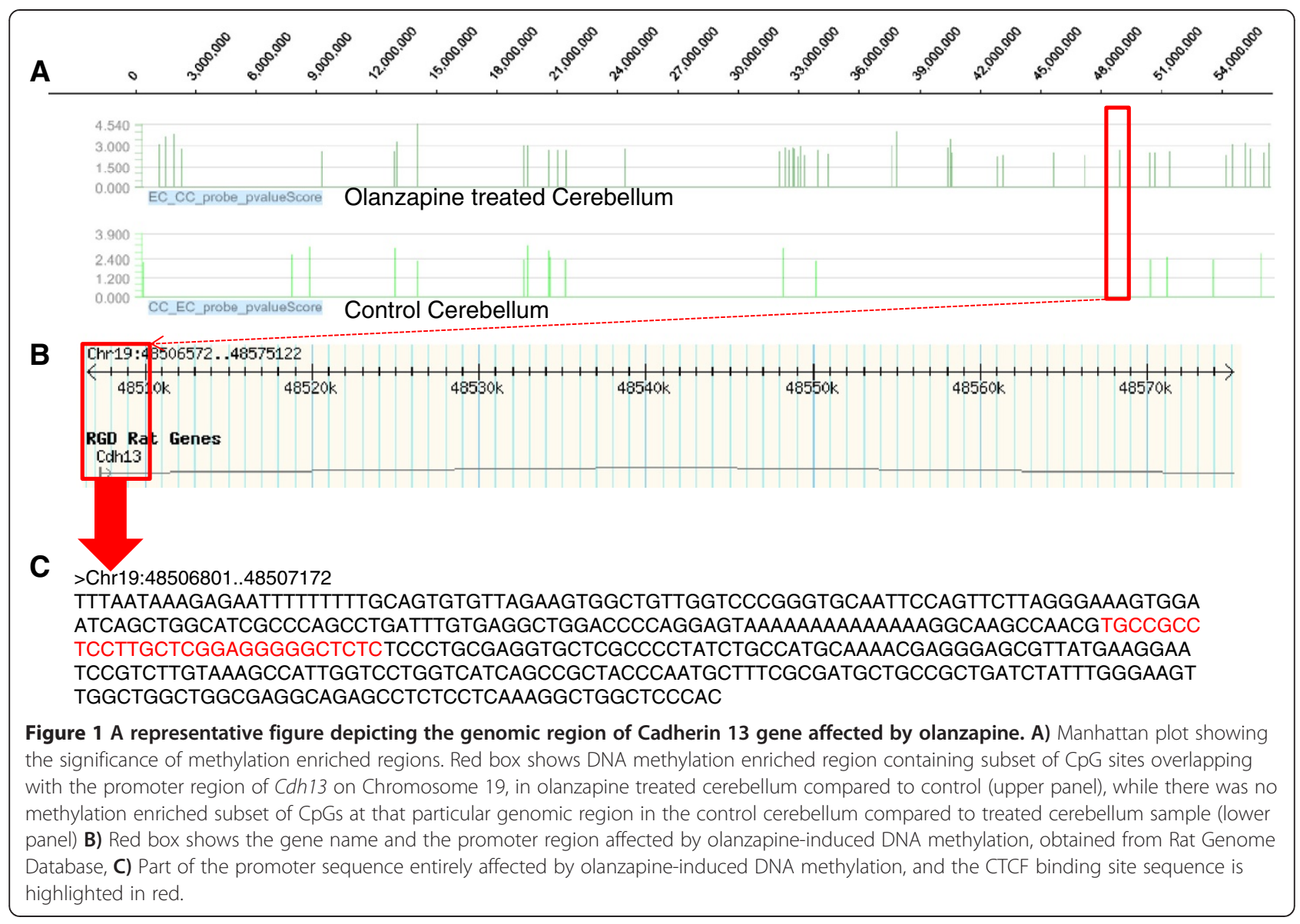

role in motor coordination [36]. The results of this study have identified that the methylation differences are specific to the promoter region of individual genes (Table 1). Also, the sequence features of these regions contain regulatory signals (Figure 1) and cellular metabolomics.
The associated cellular changes are compatible with anomalies in behavioral disorders via three specific pathways: Go12/13 signalling, RhoGDI signalling and Wnt signaling (Figure 2). Go12/13 are units of heterotrimeric $\mathrm{G}$ proteins that regulate cell processes including cell

Table 2 Top pathways, networks and molecular and cellular functions identified by pathway analysis using the Cadherin family genes affected by olanzapine

\begin{tabular}{lrr}
\hline Top canonical pathways & P-value & Number of molecules/ratio* \\
\hline Ga12/13 Signalling & $9.16 \mathrm{E}-08$ & $5 / 113(0.044)$ \\
RhoGDI Signalling & $4.76 \mathrm{E}-07$ & $5 / 166(0.03)$ \\
Signalling by Rho Family GTPases & $2.22 \mathrm{E}-06$ & $5 / 221(0.023)$ \\
Wnt/B-catenin Signalling & $1.25 \mathrm{E}-02$ & $2 / 158(0.013)$ \\
Thyroid Cancer Signalling & $4.16 \mathrm{E}-02$ & $1 / 40(0.025)$
\end{tabular}

\section{Molecular and Cellular Functions}

Cell-to-cell Signalling and interaction

$6.13 \mathrm{E}-04-3.01 \mathrm{E}-02$

Cellular movement and development

$1.09 \mathrm{E}-03-2.37 \mathrm{E}-02$

\section{Physiological System Development and Function}

Behaviour, tissue development, nervous system development and function

\section{Top Networks}

Cellular Movement, Cellular Growth and Proliferation, Cancer 


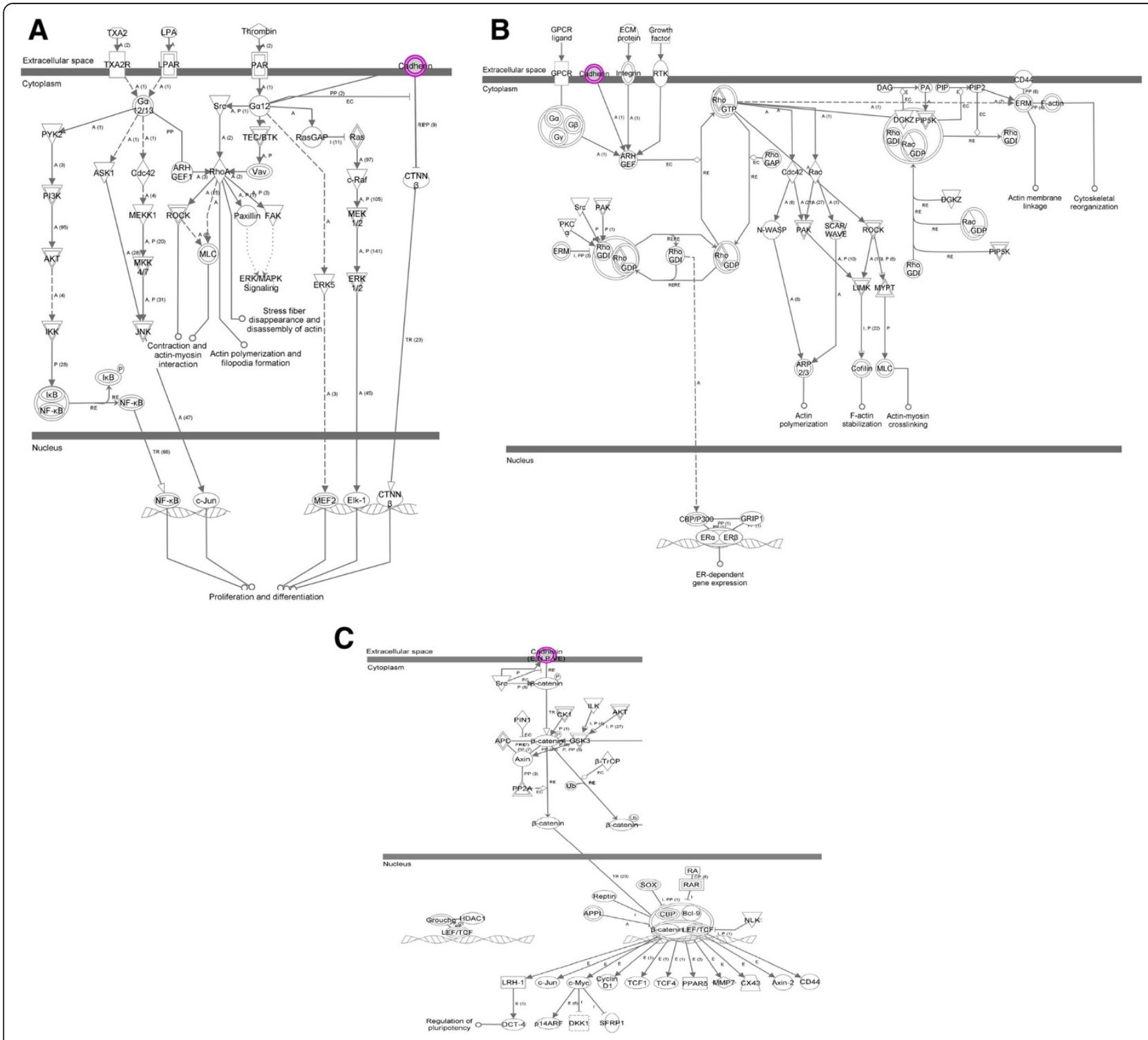

Figure 2 The most significant pathways identified by Ingenuity pathway analysis. A) Ga12/13 signalling ( $p=9.2 \mathrm{E}-08)$, B) RhoGDI signalling $(p=4.8 \mathrm{E}-07), C) W n t / \beta$-catenin signalling $(p=1.2 \mathrm{E}-02)$ significantly affected by DNA methylation of the Cadherin genes.

remodeling through the use of guanine nucleotide exchange factors [37] while Rho family proteins regulate a wide diversity of cellular processes, including adhesion, cytokinesis, cell-cell progression, membrane trafficking and signal transduction [38]. Interestingly, the Wnt signaling pathway has been implicated in the pathogenesis of schizophrenia [39] as well as negative symptom severity in psychosis [40] and it has been previously shown that E-cadherin and $\beta$-catenin affect Wnt Signaling pathway [41]. Further, aberrant expression of transcripts of the $P C D H 11 \mathrm{X} / \mathrm{Y}$ gene was reportedly implicated in anomalous cerebral asymmetry [42]. This has led to the possibility that the variation relating to psychosis and psychological disorders may not only be sequence based, but may also be mediated by antipsychotic-induced epigenetic changes [39,42]. The results on olanzapine-induced differential methylation of cadherin genes implicated in the three pathways add further support to this still evolving paradigm. Of special interest is the $P c d h 8$ gene. It has been implicated in schizophrenia [20] and has increased methylation both in hippocampus and liver in this study, suggesting that the expression of the gene is likely to be compromised due to the antipsychotic drug. The observed hypermethylation of the gene could potentially repress its transcription [22]. Moreover, there are indications that epigenetic changes affect not only a single candidate gene promoter but also intragenic sequences located farther from the transcriptional start sites [43]. The observed methylation changes are tissue-specific, 
and it is noted that the direction of methylation change (either increased or decreased methylation) is not consistent across tissues, suggesting the possibility that the changes in brain tissues are likely related to the efficacy of the drug while effects in liver may be related to the adverse consequences of the drug. Olanzapine-induced DNA methylation changes in genes involved in the identified pathways may alter the associated network functions (Table 2). However, further study is required to specifically analyze the effects (on a protein level) of gene-specific methylation changes on each identified network to unravel the specific mechanism of action of olanzapine. Also, we acknowledge that the prefrontal cortex and nucleus accumbens that are also implicated in psychosis $[44,45]$ may need to be investigated for the effect of antipsychotics on methylation, in future studies.

\section{Conclusion}

The identified pathways suggest that olanzapine-induced DNA methylation changes on the promoter regions of the Cadherin/protocadherin genes may have an important role in response to olanzapine treatment in psychosis. Further, the approach outlined in this study may be applied to other disorders of complex aetiology.

\section{Competing interests}

The authors declare that they have no competing interests.

\section{Authors' contributions}

MGM analyzed the data and wrote the first draft of the manuscript. CAC critically reviewed the manuscript for important intellectual contents. NR prepared the animals, provided animal tissues and required samples; NR and $\mathrm{RO}$ critically reviewed the manuscript for important intellectual contents. SMS co-wrote the manuscript, and critically reviewed the manuscript for important intellectual contents. All authors read and approved the final manuscript.

\section{Acknowledgements}

This research was supported by grants from the Canadian Institute of Health Research (SMS) and the Ontario Mental Health Foundation (NR), and Dr. Shiva M. Singh held a Senior Research Fellowship from the Ontario Mental Health Foundation during the course of this study.

\section{Author details}

${ }^{1}$ Molecular Genetics Unit, Department of Biology, The University of Western Ontario, London, ON N6A 5B7, Canada. ²Department of Psychiatry, The University of Western Ontario, London, ON N6A 5B7, Canada.

Received: 3 June 2014 Accepted: 26 September 2014

Published: 29 September 2014

\section{References}

1. Sasaki T, Billett E, Petronis A, Ying D, Parsons T, Macciardi FM, Meltzer HY, Lieberman J, Joffe RT, Ross CA, McInnis MG, Li SH, Kennedy JL: Psychosis and genes with trinucleotide repeat polymorphism. Hum Genet 1996, 97(2):244-246

2. Giouzeli M, Williams NA, Lonie L, DeLisi LE, Crow TJ: ProtocadherinX/Y, a candidate gene-pair for schizophrenia and schizoaffective disorder: a DHPLC investigation of genomic sequence. Am J Med Genet 2004, 129B $(1): 1-9$.

3. Toyoda S, Kawaguchi M, Kobayashi T, Tarusawa E, Toyama T, Okano M, Oda M, Nakauchi H, Yoshimura Y, Sanbo M, Hirabayashi M, Hirayama T, Hirabayashi T, Yagi T: Developmental epigenetic modification regulates stochastic expression of clustered protocadherin genes, generating single neuron diversity. Neuron 2014, 82(1):94-108.

4. Kohmura N, Senzaki K, Hamada S, Kai N, Yasuda R, Watanabe M, Ishii H, Yasuda M, Mishina M, Yagi T: Diversity revealed by a novel family of cadherins expressed in neurons at a synaptic complex. Neuron 1998, 20(6):1137-1151.

5. Wu Q, Zhang T, Cheng JF, Kim Y, Grimwood J, Schmutz J, Dickson M, Noonan JP, Zhang MQ, Myers RM, Maniatis T: Comparative DNA sequence analysis of mouse and human protocadherin gene clusters. Genome Res 2001, 11(3):389-404.

6. Miyake K, Hirasawa T, Soutome M, Itoh M, Goto Y, Endoh K, Takahashi K, Kudo S, Nakagawa T, Yokoi S, Taira T, Inazawa J, Kubota T: The protocadherins, $\mathrm{PCDHB} 1$ and $\mathrm{PCDH} 7$, are regulated by MeCP2 in neuronal cells and brain tissues: implication for pathogenesis of Rett syndrome. BMC Neurosci 2011, 12:81-2202-12-81.

7. Gu X, Xue JQ, Zhu X, Ye MS, Zhang WH: Aberrant promoter methylation of the CHD1 gene may contribute to the pathogenesis of breast cancer: a meta-analysis. Tumour Biol 2014, 35(7):6783-6790.

8. Narayan G, Scotto L, Neelakantan V, Kottoor SH, Wong AH, Loke SL, Mansukhani M, Pothuri B, Wright JD, Kaufmann AM, Schneider A, Arias-Pulido $\mathrm{H}$, Tao Q, Murty W: Protocadherin PCDH10, involved in tumor progression, is a frequent and early target of promoter hypermethylation in cervical cancer. Genes Chromosomes Cancer 2009, 48(11):983-992.

9. Yu J, Cheng YY, Tao Q, Cheung KF, Lam CN, Geng H, Tian LW, Wong YP, Tong JH, Ying JM, Jin H, To KF, Chan FK, Sung JJ: Methylation of protocadherin 10, a novel tumor suppressor, is associated with poor prognosis in patients with gastric cancer. Gastroenterology 2009, 136(2):640-51.e1.

10. Tang $X$, Yin X, Xiang T, Li H, Li F, Chen L, Ren G: Protocadherin 10 is frequently downregulated by promoter methylation and functions as a tumor suppressor gene in non-small cell lung cancer. Cancer Biomark 2012, 12(1):11-19.

11. Sugino H, Toyama T, Taguchi Y, Esumi S, Miyazaki M, Yagi T: Negative and positive effects of an IAP-LTR on nearby Pcdaalpha gene expression in the central nervous system and neuroblastoma cell lines. Gene 2004, 337:91-103.

12. Reynolds JN, Weinberg J, Clarren S, Beaulieu C, Rasmussen C, Kobor M, Dube MP, Goldowitz D: Fetal alcohol spectrum disorders: geneenvironment interactions, predictive biomarkers, and the relationship between structural alterations in the brain and functional outcomes. Semin Pediatr Neurol 2011, 18(1):49-55.

13. Erhardt A, Spoormaker VI: Translational approaches to anxiety: focus on genetics, fear extinction and brain imaging. Curr Psychiatry Rep 2013, 15(12):417-013-0417-9.

14. Dempster E, Viana J, Pidsley R, Mill J: Epigenetic studies of schizophrenia: progress, predicaments, and promises for the future. Schizophr Bull 2013 39(1):11-16.

15. Melka MG, Laufer BI, McDonald P, Castellani CA, Rajakumar N, O'Reilly R, Singh SM: The effects of olanzapine on genome-wide DNA methylation in the hippocampus and cerebellum. Clin Epigenetics 2014, 6(1):1-7083-6-1.

16. Wu YQ, Zhang WG, Tian Z, Zhang ZY: The expression of E-cadherincatenin complex in human salivary adenoid cystic carcinoma. Shanghai Kou Qiang Yi Xue 1999, 8(3):163-165.

17. Yagi T: Clustered protocadherin family. Dev Growth Differ 2008, 50(Suppl 1):S131-S140.

18. Morishita H, Yagi T: Protocadherin family: diversity, structure, and function. Curr Opin Cell Biol 2007, 19(5):584-592.

19. Krishna K, Redies C: Expression of cadherin superfamily genes in brain vascular development. J Cereb Blood Flow Metab 2009, 29(2):224-229.

20. Bray NJ, Kirov G, Owen RJ, Jacobsen NJ, Georgieva L, Williams HJ, Norton N, Spurlock G, Jones S, Zammit S, O'Donovan MC, Owen MJ: Screening the human protocadherin 8 (PCDH8) gene in schizophrenia. Genes Brain Behav 2002, 1(3):187-191.

21. Wang X, Su H, Bradley A: Molecular mechanisms governing Pcdh-gamma gene expression: evidence for a multiple promoter and cis-alternative splicing model. Genes Dev 2002, 16(15):1890-1905.

22. Kawaguchi M, Toyama T, Kaneko R, Hirayama T, Kawamura Y, Yagi T: Relationship between DNA methylation states and transcription of individual isoforms encoded by the protocadherin-alpha gene cluster. J Biol Chem 2008, 283(18):12064-12075. 
23. Tucci $V$, Kleefstra T, Hardy A, Heise I, Maggi S, Willemsen MH, Hilton $H$, Esapa C, Simon M, Buenavista MT, McGuffin LJ, Vizor L, Dodero L, Tsaftaris S, Romero R, Nillesen WN, Vissers LE, Kempers MJ, Vulto-van Silfhout AT, lqbal Z, Orlando M, Maccione A, Lassi G, Farisello P, Contestabile A, Tinarelli F, Nieus T, Raimondi A, Greco B, Cantatore D, et al: Dominant beta-catenin mutations cause intellectual disability with recognizable syndromic features. J Clin Invest 2014, 124(4):1468-1482.

24. Shishido E: Autism spectrum disorder and genes for synaptic proteins. Brain Nerve 2012, 64(1):65-70

25. Pedrosa E, Stefanescu R, Margolis B, Petruolo O, Lo Y, Nolan K, Novak T, Stopkova P, Lachman HM: Analysis of protocadherin alpha gene enhancer polymorphism in bipolar disorder and schizophrenia. Schizophr Res 2008, 102(1-3):210-219.

26. Kalmady SV, Venkatasubramanian G: Evidence for positive selection on Protocadherin Y gene in Homo sapiens: implications for schizophrenia. Schizophr Res 2009, 108(1-3):299-300.

27. Lachman HM, Petruolo OA, Pedrosa E, Novak T, Nolan K, Stopkova P. Analysis of protocadherin alpha gene deletion variant in bipolar disorder and schizophrenia. Psychiatr Genet 2008, 18(3):110-115.

28. Bardgett ME, Humphrey WM, Csernansky JG: The effects of excitotoxic hippocampal lesions in rats on risperidone- and olanzapine-induced locomotor suppression. Neuropsychopharmacology 2002, 27(6):930-938.

29. Mohn F, Weber M, Schubeler D, Roloff TC: Methylated DNA immunoprecipitation (MeDIP). Methods Mol Biol 2009, 507:55-64.

30. Bao L, Zhou M, Cui Y: CTCFBSDB: a CTCF binding site database for characterization of vertebrate genomic insulators. Nucleic Acids Res 2008 36:D83-D87.

31. Redies C, Hertel N, Hubner CA: Cadherins and neuropsychiatric disorders Brain Res 2012, 1470:130-144

32. Hirano S, Takeichi M: Cadherins in brain morphogenesis and wiring. Physiol Rev 2012, 92(2):597-634

33. Foty RA, Steinberg MS: Cadherin-mediated cell-cell adhesion and tissue segregation in relation to malignancy. Int J Dev Biol 2004, 48(5-6):397-409.

34. Nose A, Nagafuchi A, Takeichi M: Expressed recombinant cadherins mediate cell sorting in model systems. Cell 1988, 54(7):993-1001.

35. Halbleib JM, Nelson WJ: Cadherins in development: cell adhesion, sorting, and tissue morphogenesis. Genes Dev 2006, 20(23):3199-3214.

36. Strick PL, Dum RP, Fiez JA: Cerebellum and nonmotor function. Annu Rev Neurosci 2009, 32:413-434

37. Wang M, Gong B, Gu J: Expression of G-protein gamma 7 in patients with extrahepatic cholangiocarcinoma. Zhonghua Zhong Liu Za Zhi 2006, 28(10):771-772.

38. Ridley AJ: Rho family proteins: coordinating cell responses. Trends Cell Biol 2001, 11(12):471-477.

39. Freyberg Z, Ferrando SJ, Javitch JA: Roles of the Akt/GSK-3 and Wnt signaling pathways in schizophrenia and antipsychotic drug action. Am J Psychiatry 2010, 167(4):388-396.

40. Bousman CA, Glatt SJ, Chandler SD, Lohr J, Kremen WS, Tsuang MT, Everall IP: Negative Symptoms of Psychosis Correlate with Gene Expression of the Wnt/beta-Catenin Signaling Pathway in Peripheral Blood. Psychiatry J 2013, 2013:852930.

41. Konze SA, van Diepen L, Schroder A, Olmer R, Moller H, Pich A, Weissmann R, Kuss AW, Zweigerdt R, Buettner FF: Cleavage of E-cadherin and betacatenin by calpain affects Wnt signaling and spheroid formation in suspension cultures of human pluripotent stem cells. Mol Cell Proteomics 2014, 13(4):990-1007.

42. Ahn K, Huh JW, Kim DS, Ha HS, Kim YJ, Lee JR, Kim HS: Quantitative analysis of alternative transcripts of human $\mathrm{PCDH11X/Y} \mathrm{genes.} \mathrm{Am} \mathrm{J} \mathrm{Med}$ Genet B Neuropsychiatr Genet 2010, 153B(3):736-744.

43. McGowan PO, Suderman M, Sasaki A, Huang TC, Hallett M, Meaney MJ, Szyf $\mathrm{M}$ : Broad epigenetic signature of maternal care in the brain of adult rats. PLoS One 2011, 6(2):e14739.
44. Santini MA, Ratner C, Aznar S, Klein AB, Knudsen GM, Mikkelsen JD: Enhanced prefrontal serotonin $2 A$ receptor signaling in the subchronic phencyclidine mouse model of schizophrenia. J Neurosci Res 2013, 91(5):634-641.

45. Olszewski M, Piasecka J, Goda SA, Kasicki S, Hunt MJ: Antipsychotic compounds differentially modulate high-frequency oscillations in the rat nucleus accumbens: a comparison of first- and second-generation drugs. Int J Neuropsychopharmacol 2013, 16(5):1009-1020.

doi:10.1186/1471-2202-15-112

Cite this article as: Melka et al:: Olanzapine-induced methylation alters cadherin gene families and associated pathways implicated in psychosis. BMC Neuroscience 2014 15:112.

\section{Submit your next manuscript to BioMed Central and take full advantage of:}

- Convenient online submission

- Thorough peer review

- No space constraints or color figure charges

- Immediate publication on acceptance

- Inclusion in PubMed, CAS, Scopus and Google Scholar

- Research which is freely available for redistribution

Submit your manuscript at www.biomedcentral.com/submit
C BioMed Central 